\title{
SOLVENT EXTRACTION AND ENTRAINMENT PROBLEM
}

\author{
Aleksandar M. Spasic ${ }^{1 *}$, Vaso Manojlovic ${ }^{2}$, Mica Jovanovic ${ }^{2}$ \\ ${ }^{1}$ Institute for Technology of Nuclear and Other Mineral Raw Materials, \\ Belgrade, Serbia \\ ${ }^{2}$ Department of Technology \& Metallurgy, University of Belgrade, Belgrade, Serbia
}

Received 24.03.2020

Accepted 01.07.2020

\begin{abstract}
Applications of solvent extraction operations and processes play one of the most important roles in Hydrometallurgy. Therefore, in this brief review, some general concepts for selected representative applications are discussed. Also, one particular entrainment problem solution is discussed in some more details. At first, the selected general concepts for metal production of copper and uranium from their ores are presented. Then after, the leaching-solvent extraction-electro winning process for copper is shown. Finally, the extraction of uranium from wet phosphoric acid is discussed.
\end{abstract}

Keywords: solvent extraction; entrainment problems; nanoscience; nanorheology; electrocoalescence; electroviscoelasticity; breaking of emulsions; double emulsions.

\section{Introduction}

The overall world costs in the chemical industry are remarkably related to the solvent extraction (SX) of metals, e.g., Cu, Zn, Cd, Co, Ni, Au, Ag, Pt, Pd, Lanthanides, Actinides. Here, some general SX concepts for selected representative metals, $\mathrm{Cu}$ and $\mathrm{U}$, including the main relevant equipment, operations and processes, are to be discussed. In the world, more than 20 industrial plants produce about 3.9 million metric tons of copper using SX-EW (data from 2016 to 2019) [1, 2]. Therefore, as SX-EW obtains more than $16 \%$ of overall primary copper production, it is possible to consider it as one of the most critical applications in hydrometallurgy [2]. The SX-EW production is applied mainly to low-grade oxide ores and some sulfides ores, so it barely existed before the 1960s. However, as an emerging technology, the SX-EW production will increase to $18 \%$ in 2023 , as estimated by the International Copper Study Group [2]. As the representative selected metal, from radioactive rare metals, actinides, SX of uranium will be discussed. As it is well known the uranium, either as metal, carbide, or fluoride, is of substantial importance for Nuclear Energy Plants. At present, before the nuclear fusion power plants enter into

*Corresponding author: Aleksandar Spasic, a.spasic@itnms.ac.rs 
the game, for example, only in France, more than 50 nuclear reactors are used in the nuclear fission power plants producing about $75 \%$ of their overall electrical energy [3].

As an intermediary metals production segment, SX comprises that several former and later successive operations and processes are involved too. The former can be the primary mineral raw materials operations $(\mathrm{PO})$, the leaching processes (agitation, heap, in situ, biological (L), the liquids conditioning operations (C). At the same time, the latter may be the treatment of a few unwanted side effects, for example, the entrainment problems $(\mathrm{E})$, the precipitation processes $(\mathrm{P})$, the calcination processes $(\mathrm{CA})$, the reduction processes $(\mathrm{R})$, an electro-wining process $(\mathrm{EW})$.

At first, two examples will be taken as a representative to obtain metals, and discussed in some details; the copper extraction from oxide ores, and the uranium extraction from ores. The former operations, $\mathrm{PO}$ and process $\mathrm{L}$ precede the copper SX, and EW follows it, i.e., the complete short-cut to obtain the copper metal is PO-L-SXEW. Further on, the former operations, PO, and process $\mathrm{L}$ precede the uranium SX, and $\mathrm{E}, \mathrm{P}, \mathrm{CA}$, and $\mathrm{R}$ follows, that is, the complete short-cut to obtain the uranium metal is PO-L-SX-(E)-P-CA-R.

Further on, one particular example will be discussed in some details, too, that is, the L-SX-EW process for copper from oxide ores. Finally, the C-SX-(E)-P-CA-R process for uranium extraction from wet phosphoric acid, including the particular solution of the entrainment problems E, is to be presented and discussed in some more details. During the SX operations and/or processes besides the entrainment problems E, some unwanted organic liquid compounds may be formed, as well as the presence of some foams or solid impurities. Also, the extractant selectivity toward some wanted or unwanted metals have to be taken into account. The solution to these problems has to be considered either in a former liquid conditioning operations $C$, or in a later entrainment operations $E$ [4-12].

After the general presentation of SX concepts, and representative examples, including the relevant operations, processes, and equipment, the objective of this work will be a brief discussion of the particular SX of uranium including the entrainment problem solution. Since the entrainment problems are significant from both technical and economic reasons and still are challenging or not well understood, the intention is a try to elucidate or to clarify, to some extent, these problems. In the here presented and discussed examples that are supposed to justify the idea, the coalescence process will be taken as mainly responsible. However, because this event occurs at small separations, it could be more appropriate to use the term electrocoalescence process (EC). Inevitably, as the electron transfer phenomenon enters into the game, besides the heat, mass, and momentum transfer phenomena, commonly used in classical chemical engineering, it is plausible to name such background Extended Chemical Engineering. As a consequence, the EC process becomes the subject of rheology or nano-rheology and inherently enters on the border between classical and quantum mechanics or physics [6].

Three main reasons for the increasing tendency toward the applications of SX in the world are: - technical, very low content of metals in the relevant minerals/ores, including selectivity for the required metal and rejection of undesirable metals economic, the energy consumption is substantially lower, - ecological, the emissions of hazard products may be much easier controlled as well as their dangerous impact on the environment. 


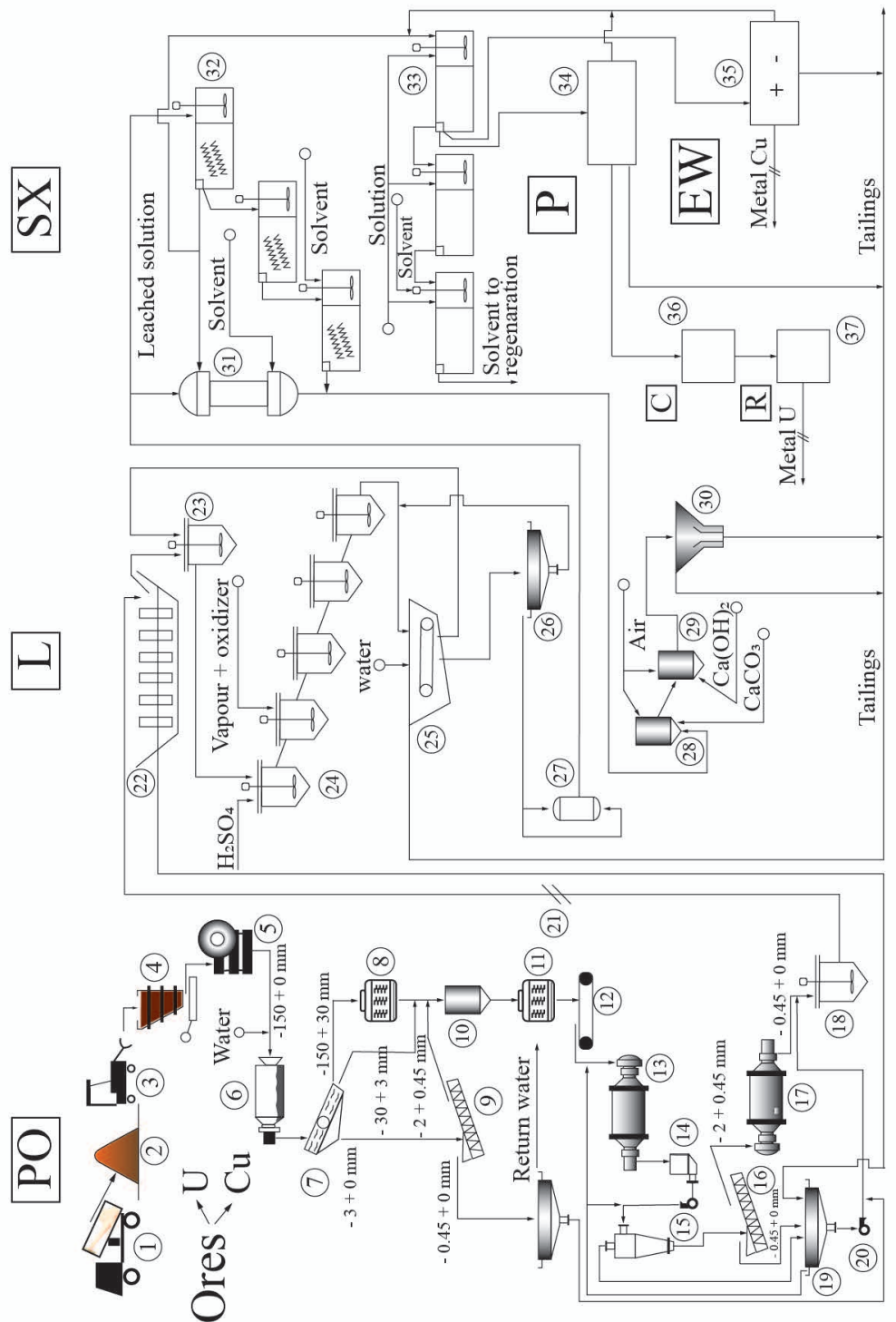

Fig. 1. A schematic flow sheet for the materials and related equipment is presented, a selected treatment of the copper and/or uranium ores. LEGEND: 1-3-Raw material/oxide ores, 4-Charger, 5-Primary crusher, 6-Washing drum, 7-Sieve, 8-Secondary crusher, 9-Classifier, 10-Sive for U, 11-Crusher, (Between the crusher and mill it is necessary to add the sieve for copper), 12-Belt conveyor, 13-Bar mill, 14-Pump, 15-Hydrocyclon, 16-Classifier, 17-Ball mill, 18-Conditioner, 19-Thickener, 20-Pump, 21-Toward leaching section, 22-Attrition machine, 23-Conditioner, 24Battery of leaching reactors, 25-Belt filter-washing, 26-Thickener-, 27-Collector-feedback into the washing 25, 28-29-Conditioners, 30-Neutralization reactor, 31-Pulse column in parallel for

$U$, 32-Battery of mixer-settlers for extraction, 33-Battery of mixer settlers for stripping, 34-

Precipitation for $U$, 35-Electro-Wining for metallic cathode copper, 36-Calcination for $U$, 37 Reduction for metallic uranium $U$. 


\section{General concepts of SX operations and processes}

Two general concepts are presented, including the number of, eventually, needed main relevant operations, processes, and equipment. Fig. 1 shows the material and equipment flow sheet for copper extraction from oxide ores PO-L-SX-EW, and uranium extraction from uranium ores PO-L-SX-P-C-R.

In the first case, copper ores enter in the section $\mathrm{PO}$, passing through the breaking or crushing operations B1-B11, further on, through the grinding and milling operations G12-G20, then enter in the section leaching L21, passing through the attrition machine A22 and the conditioner C23, then enter into the battery of leaching reactors R24, then after in the washing operation W25 and the clarifying operation C26, and finally from the collector C27 enter into the section SX, wherein parallel are the pulse column P31 and the battery of mixer-settlers M32, then after the stripping battery of mixer-settlers S33 the extract finish in the section EW 35, while the exhausted acid solutions from the pulse column P31 and the battery of mixer-settlers M32 are going in the neutralization section, the conditioners C28 and 29, and finally in the reactor for neutralization N30.

In the second case, for uranium ores, a general concept is similar to the position $\mathrm{S} 33$, then the difference appears, i.e., the extract is going into the precipitation process $\mathrm{P} 34$, further on trough the calcination process $\mathrm{C} 36$, and reduction process R37.

\section{Solvent extraction from copper oxide ores}

In this example, Fig. 2 presents a simplified liquids flow sheet through the appropriate equipment for the copper L-SX-EW process.

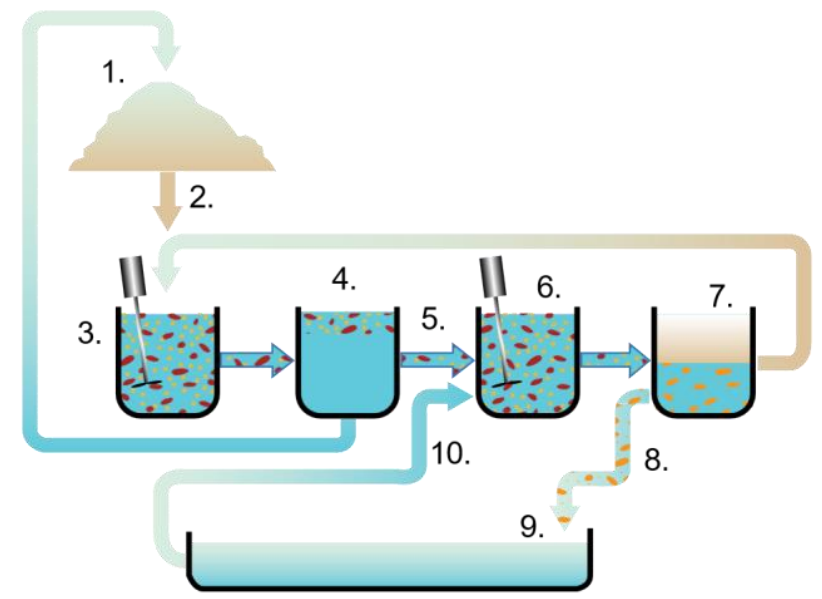

Fig. 2. A simplified schematic flow sheet for the L-SX-EW process from copper oxide ores.

In the beginning, the heap 1 is brought in contact with diluted sulfuric acid, then the sulfuric solution 2, with the copper and other diluted metals, is lead into the mixer with organic phase 3 , further on, in the settler, the water phase of dispersion 4 is separated from the organic phase 5 , then the water phase 4 is feedback into the heap, and the organic phase 5 , rich with metallic copper, is lead to stripping mixer 6 , where it is mixed with the stripping solution, i.e., the strong acid/weak electrolyte, then in the settler 8 the copper is 
stripped from the organic phase into the rich electrolyte, and the organic phase 7 is feedback in the mixer 3. Finally, the concentrated acid solution, rich electrolyte, is leading into the EW cells 9, and then, at the end of the EW process the concentrated acid solution, weak electrolyte, 10 is feedback into the stripping mixer 6 .

Solvent Extraction of uranium from wet phosphoric acid

The second, more detailed, concept is related to the radioactive rare metals, actinides; as a representative concept, the uranium SX from wet phosphoric acid is to be discussed. Here, the entrainment loop $\mathrm{E}$ is introduced as one additional later operation and process sequence which is to be discussed in particular. In Fig. 3 a schematic flow sheet for the uranium C-SX-(E)-P-CA-R operations, processes and equipment is presented.

It is usual that such, or somehow similar, concept is applied as one bypass plant in the industrial plants for phosphoric acid or fertilizers. This concept may contain seven main parts, that is, the conditioning operations, two cycles of solvent extraction, the cycle of reductive stripping and precipitation, the entrainment section, the calcination and reduction sections.

In the first section I, the phosphoric acid, e.g., from the industrial plant, enter the heat exchanger 1 , to be cooled, and then into the thickener 2 , vacuum filter 3 , and adsorption column 4 . Hence, the conditioned acid enters in the extraction cycle II, at first in the oxidation reactor 5 , then after in the battery of four mixer-settlers extraction units 6 , where the acid is mixed with the organic phase, e.g., the synergistic mixture D2EHPATOPO in dearomatized kerosene, or some newer and more effective organic mixture, then the organic phase, enriched with uranium, is going in the battery of three mixer-settler stripping units 7 , where this organic phase is mixed with the acid from reduction reactor 8. Now, the stripping cycle III, the phosphoric acid, enriched with uranium, enter into the battery of four mixer-settler extraction units 9, wherefrom the organic phase, enriched with uranium, go in three mixer-settler washing units 10 , and further into two mixersettler stripping units 11; finally, the enriched phosphoric acid is going in the crystallizer columns 12, where the ammonium di- or three-hydro-uranate is precipitated IV. The next section $\mathrm{V}$, the phosphoric acid, with low content of uranium, which includes the entrained organic phase, in the form of the double emulsion, is going from the extraction mixersettler battery 6 into the lamellar coalescer 13, from where the separated organic phase is feedback into the extraction cycle II, and the phosphoric acid is going in four air induced flotation cells 14, wherefrom the overflow is going into the lamellar coalescer 15 , and underflow, the phosphoric acid in the collector tank 16. At the end of this section $\mathrm{V}$, the phosphoric acid with low content of uranium and with a minimum of the entrained organic phase is returned in the industrial plant for further treatment VI. In section VII, the precipitate, ammonium di- or three-hydro-uranate (yellowcake) IV is going in the calcination section 17, and further on in the reduction section 18. Finally, the uranium metal $\mathrm{U}$ is obtained. 


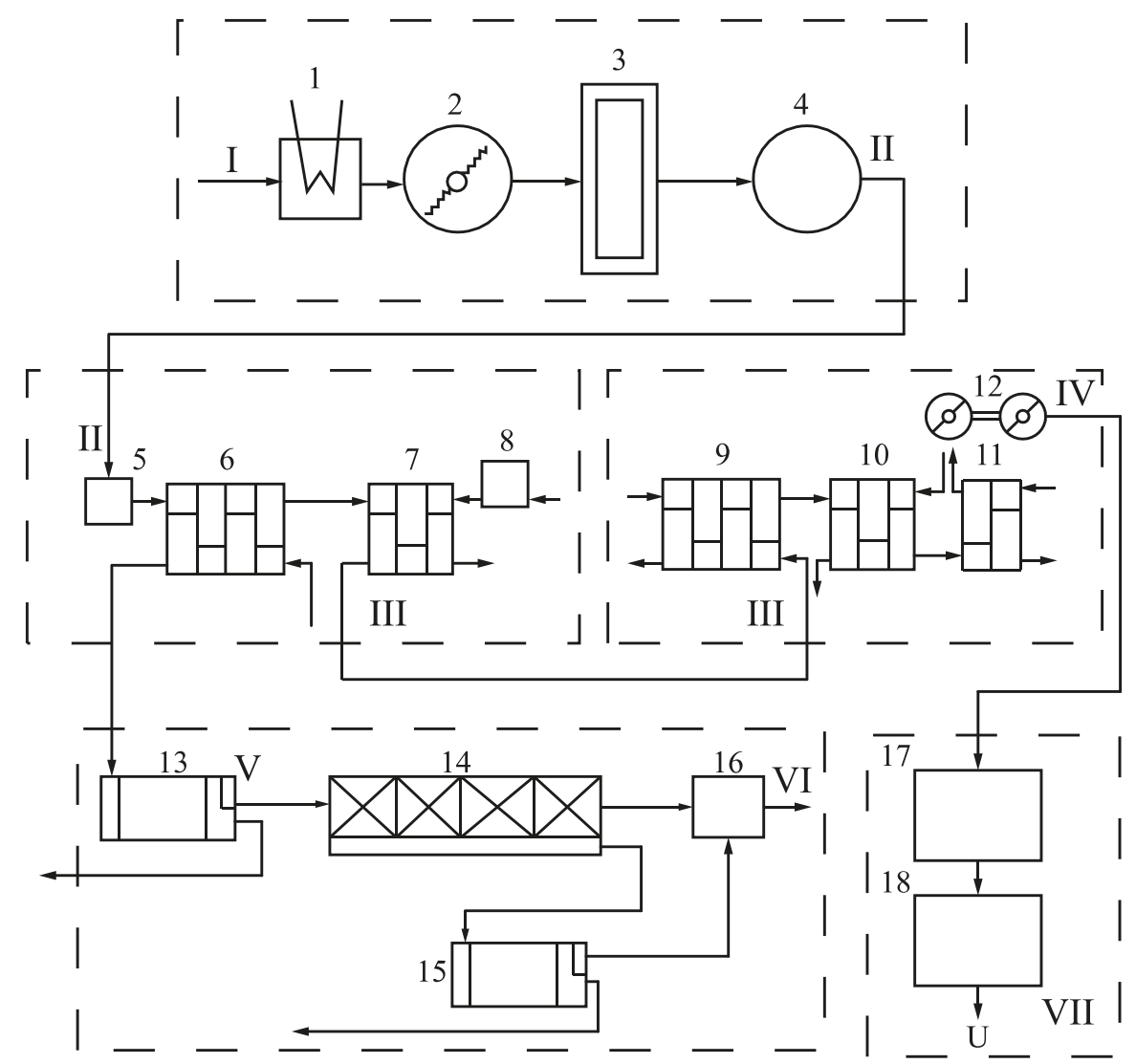

Fig. 3. A schematic flow sheet of the selected operations, processes, and equipment. LEGEND: 1-Cooler; 2-Thickener; 3-Vacuum filter; 4-Adsorption column; 5-Oxidation reactor; 6-Four Mixer-Settler-Extraction units; 7-Three Mixer-Settler-Reduction Stripping units; 8-Reduction reactor; 9-Four Mixer-Settler-Extraction units; 10-Three Mixer-Settler-Washing units; 11-Two Mixer-Settler-Reduction-Stripping units; 12-Two crystallizer units; 13-Lamellar coalescer; 14-Four Air-Induced-Flotation cells; 15 Settler; 16-Raffinate tank; 17-Calcination reactor; 18-Reduction reactor.

\section{Entrainment problem solution}

Now, the particular entrainment problem solution is to be discussed in some details. Following the adopted methodology at first, the entrainment section design will be elaborated. The representative example is taken from the pilot plant for uranium extraction from wet phosphoric acid by the D2EHPA-TOPO process [13-16]. The main idea for this process was developed by Oak Ridge National Laboratory, USA, and later on, using this idea Institute for Technology of Nuclear and Other Mineral Raw Materials (ITNMS), Serbia has developed, designed, and constructed the pilot plant as a by-pass plant in the fertilizers factory Prahovo, Serbia [17-28]. 
The light phase loop

A particular section for the presented entrainment problem solution was designed, constructed, and applied in the by-pass pilot plant. The pilot plant, presented in Fig. 3 was running six years in the campaigns of two months per year. All necessary details of the light phase loop are presented in Fig. 4.

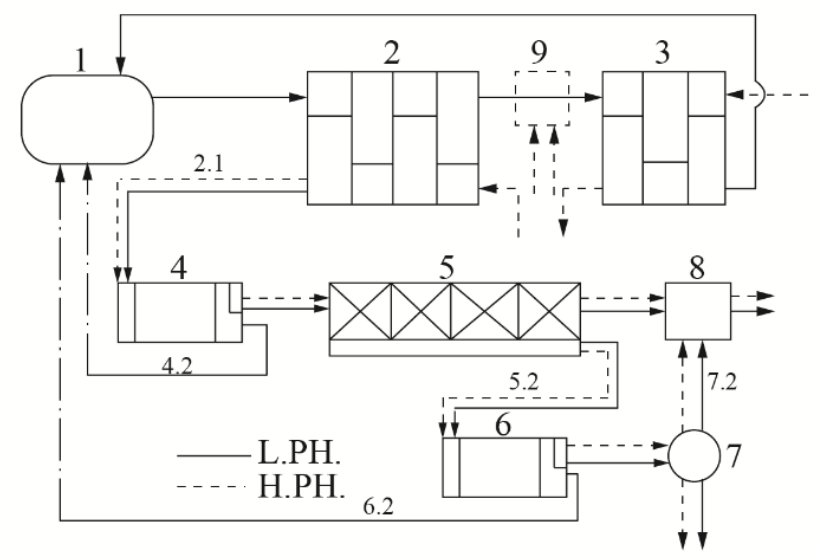

Fig. 4. The light phase loop.

LEGEND: 1-Light phase tank, 2-Mixer-settler extraction units, 3-Mixer-settler reduction stripping units, 4-Lamellar coalescer-central unit, 5-Flotation units, 6-Settler unit, $7-$ Adsorption column unit, 8-Raffinate tank, 9-Light phase collector tank.

From the mixer-settler extraction units 2 the heavy phase, phosphoric acid, together with the entrained light phase in the form of a double emulsion, enter in the lamellar coalescer 4. Further on, from the lamellar coalescer 4, considered as the central unit in the entrainment section, the heavy phase continues into the battery of four air induced flotation cells 5, wherefrom to the settler unit 6 , and the adsorption column unit 7. Finally, the heavy phase raffinate is collected from the battery of flotation cells underflow 5 and from the adsorption column output 7 into the raffinate tank 8 , and then feedback into the industrial plant. Hence, the raffinate, phosphoric acid, with very low contents of uranium and the entrained light phase is convenient for further fertilizer production processes. To mention two main reasons, technical and economic, for the application of the entrainment section: the first, technical, is corrosive action of the light phase, synergistic mixture of D2EHPA-TOPO in dearomatized kerosene, on the rubberlined processes equipment in the industrial fertilizer plant, and the second, economic, very high price of the organic phase components, D2EHPA and TOPO or some other organic phase components developed later as more efficient.

Central unit in the entrainment section-the lamellar coalescer

A schematic cross-section and design parameters of the lamellar coalescer, considered as the central unit for the breaking of double emulsion in the entrainment section, are presented in Fig. 5. 


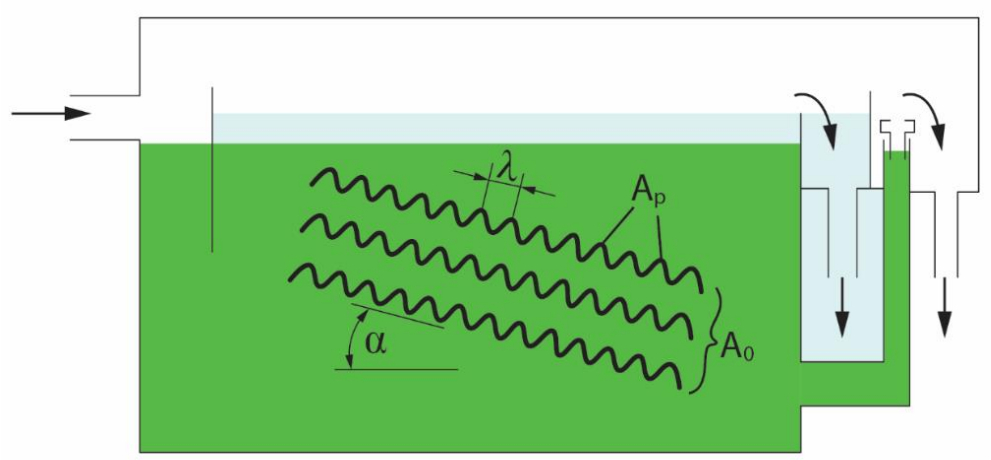

Fig. 5. A schematic cross-section of the lamellar coalescer, including its design parameters: overall area $A_{o}$, area of perforations at the tops $A_{p}$, the inclination angle $\alpha$, and distance between two consecutive tops $\lambda$.

The mathematical models, overall volume balance model, reduced semiempirical mathematical model, and simple population balance model were developed and used for designing of the lamellar coalescer; their details may be found in the references $[6,7]$.

\section{Breaking of double emulsions on an inclined plate}

It is important to understand the events and/or physical processes that occur in the lamellar coalescer during the breaking of finely dispersed systems, double emulsions [2947]. The physical picture of the events in this equipment may be presented as the succession of the following successive sequences: approach, rest, disturbance, rupture, coalescence or electrocoalescence, and flow up. This physical picture, including all mentioned sequences, is presented in Fig. 6. A further and more in-depth clarification of the involved events and physical processes can be found in the references $[6,7]$.

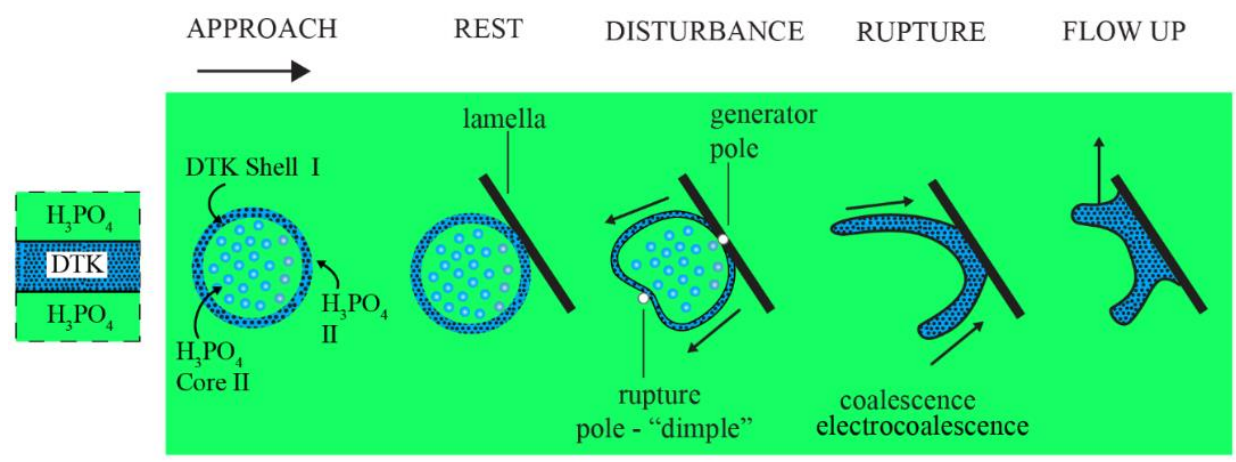

Fig. 6. The physical model of the processes during the breaking of double emulsion on an inclined plate is presented by the sequences approach rest and disturbance, rupture and flow up. Source: [6] and [47]. Reprinted with permission from Elsevier Science. 


\section{EC process}

Only a brief review of the two less known and/or understood sequences are to be presented here, these are disturbance and rupture, including the EC process, but much more details may be found in the references [6,7]. Hence, a corresponding constitutive model of liquids was developed and applied to the selected double emulsion. Considering Marangoni instabilities of the first order and possible electrical analogue, the EC process, in some extent, was elucidated. The Marangoni instability of the first order has been explained theoretically in $[6,7,47-50]$. It is shown that if there is an adverse temperature gradient of high enough magnitude across a thin liquid film with a free surface, such a layer could become unstable and lead to cellular convection. Hence, such a small disturbance may cause a film of initially uniform thickness to be locally heated at a point on the interface; that results in a decreased surface tension and a surface tension gradient which leads to induced motion tangential to the surface away from the point of local heating. Taking into account mass conservation, this motion induces a motion of the bulk phase, which is warmer than the liquid-liquid interface, toward the surface. Also, this story can be interpreted as a thermal Peclet ratio, which presents a measure of the ratio between heat transport by convection, due to surface tension gradients, and bulk heat transport by conduction. Now, because the forces of electrical origin become dominant at small separations, that is, at nano, and atto scale it may be possible to redefine the parameters with the changes relevant to the nature of forces involved; thus, forming the electrical analog of Marangoni instability mechanism is permitted, which is shown in Fig. 7.

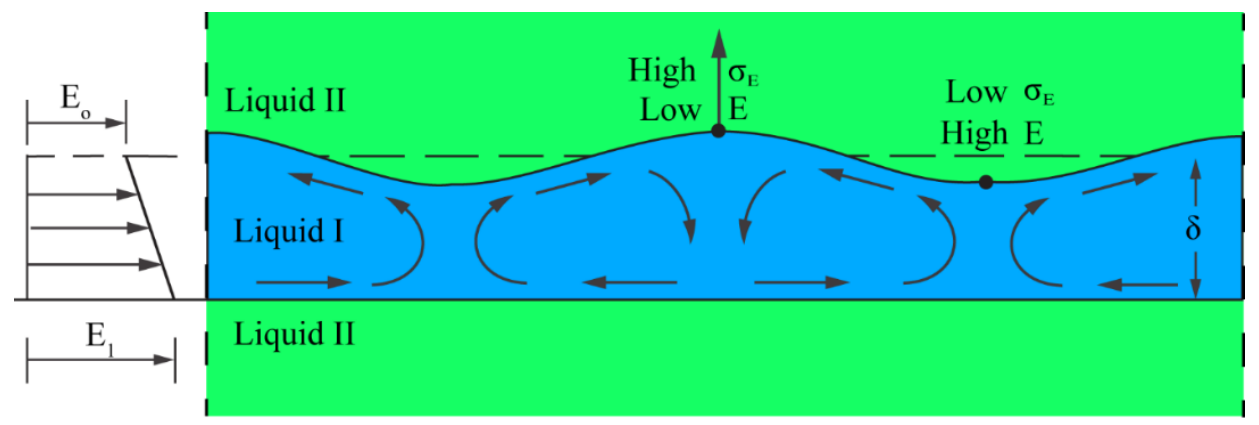

Fig. 7. The electrical analogue of the Marangoni instability mechanism. Liquid I - DTK, Liquid II - $\mathrm{H}_{3} \mathrm{PO}_{4}, \mathrm{E}$ - the electrical potential difference between liquid layers, $\sigma_{E}-$ the electrical interfacial potential (EIP), $\delta$ - the film thickness. Source: [6] and [47]. Reprinted with permission from Elsevier Science. 
Further on, taking into account the presented electrical analogue of Marangoni instability and developed theory of electroviscoelasticity, both based on electrohydrodynamics principles, the physical picture of the EC process is shown in Fig. 8.

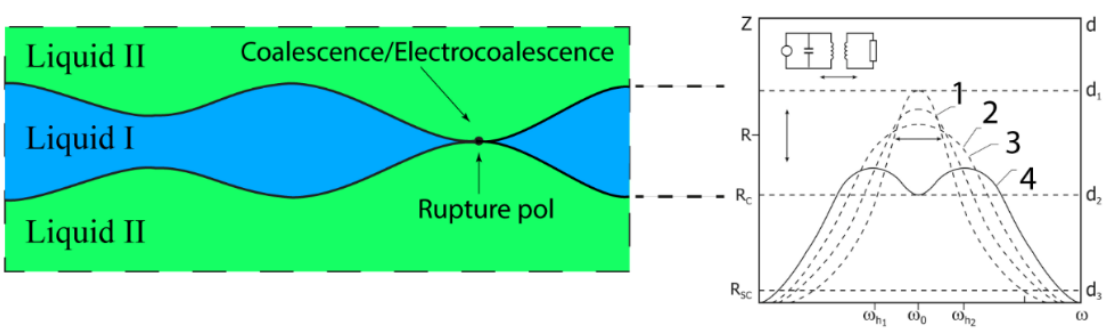

(a)

(b)

Fig. 8. The physical picture of the EC process based on Marangoni instability and theory of electroviscoelasticity; (a) the double emulsion-rupture pole,

(b) the correlation impedance-frequency for an equivalent antenna output circuit, showing a sharpness of resonance; as can be seen at the moment of rupture, at the curve 4 -overcoupling, low circuit factor of merit $Q$ becomes significant and coalescencelelectrocoalescence occurs. Source: [6] and [47]. Reprinted with permission from Elsevier Science.

Finally, both the qualitative and quantitative physical pictures of the EC process are presented and discussed in more detail in Ref. [6, 7, 47, 50].

\section{Conclusions}

The presented material in this brief review may help readers to obtain some general insight into the SX of metals, with several operations, processes, and equipment involved. Examples were selected to represent the two significant concepts for SX of metals, that is, a copper and $\mathrm{U}$, including the main, necessary, former and later operations and processes. Also, one particular entrainment problem solution is discussed to some extent. Further and more in-depth details, containing an introduction into the quantum aspects and implications of the EC process, as well as the complete list of relevant references, may be found in a cited books and papers.

\section{Acknowledgment}

The financial support for the fundamental research projects grants no. 101822 and 142034 realized at ITNMS, and recent R \& D projects grant no. 34009 and 46010 realized in collaboration with the Faculty of Technology and Metallurgy, University of BelgradeBelgrade-Serbia, arrived from the Ministry of Science and Technology of the Republic of Serbia. 


\section{References}

[1] U.S. Geological Survey, Mineral Commodity Summaries, January 2020, COPPER,

https://pubs.usgs.gov/periodicals/mcs2020/mcs2020-copper.pdf, Accessed 25 June 2020

[2] International copper study group "The world copper factbook 2019" https://www.icsg.org/index.php/component/jdownloads/finish/170-publicationspress-releases/2965-2019-10-29-icsg-factbook-2019?Itemid=0, Accessed 25 June 2020.

[3] World Nuclear Association, "Nuclear Power in France", (Updated March 2020), https://www.world-nuclear.org/information-library/country-profiles/countries-af/france.aspx Accessed 25 June 2020.

[4] T. Smolinski, D. Wawszczak, A. Deptula, W. Lada, T. Olczak, M. Rogowski, M. Pyszynska, A.G. Chmielewski; J Radioanal Nucl Chem, 314 (2017) 69-75.

[5] M.C. Ruiz, J. Risso, J. Seguel, R. Padilla: Minerals Engineering, 146 (2020) 1-7.

[6] A.M. Spasic: Rheology of Emulsions - electrohydrodynamics principles, Academic Press-Elsevier, London, 2018.

[7] J-P. Hsu, A.M. Spasic: Interfacial Electroviscoelasticity and Electrophoresis, CRC Press-Taylor \& Francis Group, Boca Raton London New York, 2010.

[8] A.M. Spasic, J-P. Hsu (Eds.): Finely Dispersed Particles - Micro-, Nano-, and Atto-Engineering, CRC Press-Taylor \& Francis Group, Boca Raton London New York, 2005.

[9] M.D. Babic, A.M. Spasic, M.M. Marinko, N.N. Djokovic: Uranium in Phosphoric Fertilizers and Possibility of Its Elimination, Book LXXII SANU, Belgrade, 1993.

[10] A.M. Spasic In: A.V. Delgado (Ed.): Interfacial Elektrocinetics and Elektrophoresis, Marcel Dekker, Inc., New York Basel, 2002, Ch. 30, p. 837.

[11] R. Stevanovic In: A.M. Spasic (Ed.): Visefazni disperzni sistemi, ITNMSAkademija, Belgrade, 1997, Ch. 3, p. 119. In Serbian.

[12] A.M. Spasic In: A.M. Spasic (Ed.): Visefazni disperzni sistemi, ITNMSAkademija, Belgrade, 1997, Ch. 1, p. 1. In Serbian.

[13] V. Pavasovic, R. Stevanovic, J. Prochazka, In: International Solvent Extraction Conference, Munchen, Germany, 1986, Vol. III, p. 107.

[14] J.H. Holmes, A.C. Schafer: CEP, 52 (1956) 201-204.

[15] R. Siebenhofer, R. Marr, In: International Solvent Extraction Conference, Munchen, Germany, 1986, Vol. III, p. 281.

[16] A. Moral, G. Cordero, J.M. Josa In: $2^{\text {nd }}$ International Congress on Phosphoric Compounds, Boston, Massachusets, USA, 1979, p. 693.

[17] M.D. Babic, et al., In: $9^{\text {th }}$ International Congress of Chemical and Process Engineering, Prague, Czech Republic, 1987, p. D 3.70.

[18] D. Negoicic, N. Djokovic, A. Spasic, M. Babic, A, Tolic In: Proc. $2^{\text {nd }}$ Yugoslav Congress on Chemical Engineering and Process Technique, Dubrovnik, Yugoslavia, 1987, p. 269.

[19] J.E. Lawver: Minn Eng, 7 (1962) 46-51.

[20] M.D. Babic, A.M. Spasic, M.M. Marinko, N.N. Djokovic In: B. Merkel, S. Hurst, E.P. Lohnert, W. Struckmeier, Eds. Geophysical Congress, Uranium-Mining and Hydrogeology, Bergakademie-Freiberg, Sachsen, Verlag Sven von Loga, Keln, Germany, 1995, p. 9. 
[21] A.M. Spasic, N.N. Djokovic, N. Canic, M.D. Babic, A.S. Tolic In: $9^{\text {th }}$ International Congress of Chemical and Process Engineering, Prague, Czech Republic, 1987, p. D 3.72 .

[22] A.M. Spasic, N.N. Djokovic, M.D. Babic In: $4^{\text {th }}$ Mediteranean Congress on Chemical Engineering, Barcelona, Spain, 1987, p. 372.

[23] A.M. Spasic, N.N. Djokovic, M.D. Babic, G.N. Jovanovic In: $11^{\text {th }}$ International Congress of Chemical and Process Engineering, Prague, Czech Republic, 1993, p. D9 23.

[24] A.M. Spasic, N.N. Djokovic, M.D. Babic, G.N. Jovanovic In: $11^{\text {th }}$ International Congress of Chemical and Process Engineering, Prague, Czech Republic, 1993, p. D9 24.

[25] A.M. Spasic, N.N. Djokovic, N. Canic, M.D. Babic In: International Solvent Extraction Conference, Moscow, Rusia, 1988, Vol IV, p 227.

[26] J.C. Godfrey, C. Hanson, M.J. Slater, Sh. Tharmalingam: AIChE Symp.Ser. 74 (1978) 127-133.

[27] J.C. Godfrey: The Formation of Liquid-Liquid Dispersions-Chemical and Engineering Aspects-Flow Phenomena of Liquid-Liquid Dispersions in Process Equipment, Inst of Chem Eng, London, 1984.

[28] T.C. Lo, M. Baird, C. Hanson (Eds.): Handbook of solvent extraction, Wiley, New York, 1983.

[29] A.M. Spasic: Chem Eng Sci, 47 (1992) 3949-3957.

[30] S. Hartland, S.M. Wood: AIChE J, 19 (1983) 810-817.

[31] D.D. Joseph: Fluid dynamics of viscoelastic liquids, Springer Verlag, New York Berlin Heidelberg London Paris Tokyo Hong Kong, 1990.

[32] R.M. Christensen: Theory of viscoelasticity, Academic Press, New York London, 1971.

[33] A.G. Turner: Heat and concentration waves, Academic Press, New York, 1972.

[34] S.H. Davis: J Appl Mech, 50 (1993) 977-982.

[35] T.D. Gurkov, B. Nenova, E.K. Kostova, W. Gashler In: P. Kralchevsky, R. Miller, F. Ravera (Eds.): Colloid and interface chemistry for nanotechnology, CRC PressTaylor \& Francis Group, Boca Raton London New York, 2014, Ch. 15, p. 351.

[36] D.B. Strukov, G.S. Snider, D.R. Stewart, S.R. Wiliams: Nature, 453 (2008) 80-83.

[37] E.A. Buo: Nonequilibrium quantum transport physics in nanosystems. World Scientific, New Jersey London Singapur Beijing Shanghai Hong Kong Taipei Chennai, 2009.

[38] W. Spisak: Nature, 349 (1991) 23.

[39] E.U. Condon, H. Odishaw (Eds.): Handbook of Physics. McGraw Hill, New York, 1958.

[40] M.A. Garstens: J Appl Phys, 50 (1957) 352-356.

[41] J.L. Eriksen: Isledovanie po mehanike splosnih sred, Mir, Moscow, 1977. In Russian.

[42] T.P. Andjelic: Tenzorski racun, Naucna Knjiga, Beograd, 1967. In Serbian

[43] M. Plavsic: Mehanika viskoznih fluida, Prirodno Matematicki Fakultet Beograd, Beograd, 1986. In Serbian.

[44] A.M. Spasic, M.P. Lazarevic: J Colloid Interface Sci, 316 (2007) 984-995.

[45] M.P. Lazarevic, A.M. Spasic: Math Comput Mod, 49 (2008) 475-481.

[46] W.I. Orr (Ed.):: Radio handbook, 17th ed., Editors and Engineers-New Augusta: Ltd, New Augusta-Indiana, 1967. 
[47] A.M. Spasic, J.M. Jovanovic, M. Jovanovic: Adv Colloid Interface Sci, 174 (2012) 31-49.

[48] R.F. Probstein, Physicochemical Hydrodynamics, Wiley, New York, 1994.

[49] H.R. Kroyt, Colloid Science. Elsevier, Amsterdam, 1952.

[50] A.M. Spasic, J.M. Jovanovic, V. Manojlovic, M. Jovanovic: J Colloid Interface Sci, 479 (2016) 165-172.

\section{(c) (†) Creative Commons License}

This work is licensed under a Creative Commons Attribution 4.0 International License. 